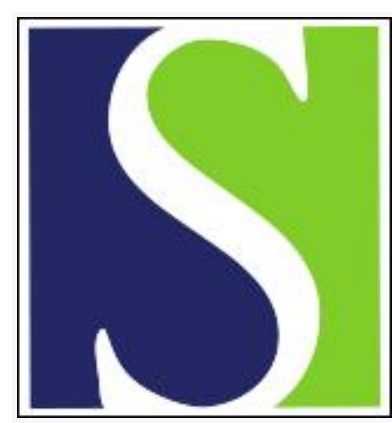

Scand J Work Environ Health 1998;24(2):138-144

https://doi.org/10.5271/sjweh.291

Issue date: Apr 1998

Vibration-induced white finger and cold response of digital arterial vessels in occupational groups with various patterns of exposure to hand-transmitted vibration

by Bovenzi M

The following article refers to this text: 2001;27 suppl 1:1-102

Key terms: cold provocation test; exposure-response relationship; finger systolic blood pressure; predictive value; sensitivity; specificity; vibrating tool

This article in PubMed: www.ncbi.nlm.nih.gov/pubmed/9630062 


\title{
Vibration-induced white finger and cold response of digital arterial vessels in occupational groups with various patterns of exposure to hand-transmitted vibration
}

\author{
by Massimo Bovenzi, MD
}

\begin{abstract}
Bovenzi M. Vibration-induced white finger and cold response of digital arterial vessels in occupational groups with various patterns of exposure to hand-transmitted vibration. Scand J Work Environ Health 1998;24(2):138-44.

Objective This study investigated the relation between vibration exposure, the prevalence of white fingers, and the cold response of digital arterial vessels in workers using vibrating tools.

Methods The change in finger systolic blood pressure (FSBP) at 15 and $10^{\circ} \mathrm{C}$ as the percentage of the pressure at $30^{\circ} \mathrm{C}$ (FSBP\%) was measured in 455 healthy referents and 822 workers exposed to handtransmitted vibration. Exposure to hand-transmitted vibration was assessed in terms of 8-hour energyequivalent frequency-weighted acceleration $[\mathrm{A}(8)]$ and total operating time with vibrating tools.

Results The prevalence of white fingers was $1.1 \%$ for the referents and ranged from $9.0 \%$ to $51.6 \%$ for the vibration-exposed groups. The estimated mean value of $\mathrm{A}(8)$ ranged between 1.6 (referents) and 8.3 (quarry drillers) $\mathrm{m} / \mathrm{s}^{2}$. After adjustment for age, smoking, and drinking habits, the FSBP\% was significantly lower in the vibration-exposed groups than in the reference group. Groupwise, the FSBP $\%_{10}$. was inversely related to the prevalence of white fingers, the estimated $\mathrm{A}(8)$, and total operating time. With FSBP $\%_{10^{\circ}}<70 \%$ or $<60 \%$ as the Iower normal limit, the sensitivity of the cold test varied from $86 \%$ to $100 \%$, with a specificity of $90 \%$ to $94 \%$, and a positive predictive value of $68 \%$ to $74 \%$.

Conclusions FSBP measurement during cold provocation is a useful laboratory test for white fingers. A quantitative relationship between cold-induced digital arterial hyperresponsiveness and occupational exposure to hand-transmitted vibration was suggested.
\end{abstract}

Key terms cold provocation test, exposure-response relationship, finger systolic blood pressure, predictive value, sensitivity, specificity, vibrating tools.

The anamnestic diagnosis of Raynaud's phenomenon in vibration-exposed workers is based on a positive history of cold-induced episodes of white finger occurring after the start of occupational exposure to hand-transmitted vibration (1). The use of color charts or hand photographs displaying the finger blanching that occurs during a typical Raynaud attack (2) may assist the anamnestic diagnosis of white fingers. A positive cold provocation test combined with a reliable history of finger blanching attacks definitively supports the diagnosis of vibration-induced white fingers (VWF), providing that primary Raynaud's phenomenon or other causes of secondary Raynaud's phenomenon are excluded.

Among the several laboratory tests used to detect white fingers, the measurement of finger systolic blood pressure (FSBP) during a standardized cooling procedure is consid- ered one of the most promising means of quantifying the degree of cold-induced digital vasospasm in vibration-exposed workers. The accuracy of FSBP measurement during cooling in the detection of white fingers has been assessed mainly in clinical or laboratory work using either small groups of vibration-exposed workers or patients diagnosed consecutively with mild to severe white fingers (3-8). There is a shortage of epidemiologic data on the usefulness of FSBP testing methods in assessments of white fingers in worker groups with different patterns of exposure to hand-transmitted vibration. The purpose of this study was to investigate the relation between vibration exposure, the prevalence of white fingers and the cold response in the digital arterial vessels of workers who used vibrating tools in various sectors of industry, such as manufacturing, construction, quarrying, and forestry.

1 Institute of Occupational Medicine, University of Trieste, Centro Tumori, Trieste, Italy.

Reprint requests to: Dr Massimo Bovenzi, Istituto di Medicina del Lavoro, Università di Trieste, Centro Tumori, Via della Pietà 19 , I-34129 Trieste, Italy. [e-mail: bovenzi@univ.trieste.it] 


\section{Subjects and methods}

\section{Subjects and medical investigations}

Eight hundred and twenty-two vibration-exposed workers underwent a medical interview and a physical examination between October and April in 1989-1996. These workers represented $90 \%$ of a total sample of vibration-exposed workers who were initially screened by a standardized health questionnaire (9) validated with a medical interview. The reasons for exclusion from further medical investigations were the presence of cardiovascular, neurological, or metabolic diseases requiring medication, previous severe injuries of the fingers and hands, and a positive family history of white fingers. After these selection criteria were applied, the surveyed population included 100 grinders and 140 mechanics employed in mechanical engineering and vehicle manufacture, 65 caulkers and 132 operators using vibrating tools in ship building and repairing, 31 foundry workers, 148 construction workers, 41 quarry drillers, and 165 forest workers. The groups of caulkers, shipyard workers, foundry workers, quarry drillers, and forest workers included all the vibrationexposed workers employed in 5 firms or companies, while the grinders, mechanics, and construction workers represented random samples of operators who used vibrating tools in 6 establishments.

The anamnestic diagnosis of VWF was based on a positive history of blanching attacks involving $\geq 1$ fingers and occurring after the start of exposure to vibration produced by hand-held power tools. The severity of VWF was rated according to the Stockholm scale (10).

Four hundred and fifty-five healthy men, tested during the last decade at the vascular laboratory of the University of Trieste's Institute of Occupational Medicine, served as refer- ents. These subjects were white-collar workers $(\mathrm{N}=152)$ or manual workers $(\mathrm{N}=303)$ not exposed to physical or chemical agents known to cause vasospastic symptoms, such as hand-transmitted vibration, extreme cold environment, vinyl chloride, and arsenic. All the white-collar workers and twothirds of the manual workers were recruited from the same firms or companies as the vibration-exposed workers. The remaining manual workers who were referents were randomly recruited from a population of industrial operators who attended annual compulsory medical examinations. The male referents underwent the same medical procedures used as the vibration-exposed workers. Cigarette smoking and alcohol consumption were carefully investigated in both groups. The characteristics of the study populations are reported in table 1.

\section{Finger systolic blood pressure and cold provocation test}

The cold test was performed with the subject in a supine position after a rest period of $20-30$ minutes in a laboratory room with an ambient temperature of $21-23^{\circ} \mathrm{C}$. FSBP was measured after the cold provocation of a test finger according to the technique proposed by Nielsen \& Lassen (11). A double inlet plastic cuff for both air filling and water perfusion was placed around the middle phalanx of the third left finger of the referents and the vibration-exposed workers without white fingers. In the subjects with a positive anamnesis for white fingers, the most affected finger was cooled. The test finger was thermostated with water circulating at 30 , 15 , or $10^{\circ} \mathrm{C}$ by using a digit cooling system (Medimatic A/S, Copenhagen, Denmark). Two air-filled cuffs were applied to the proximal phalanx of the test finger (for ischemia during cooling) and to the middle phalanx of a reference

Table 1. Characteristics of the study populations. $[A(8)=8$-hour energy-equivalent frequency-weighted acceleration]

\begin{tabular}{|c|c|c|c|c|c|c|c|c|c|c|c|c|c|c|c|c|}
\hline \multirow[t]{2}{*}{ Group } & \multicolumn{2}{|c|}{$\begin{array}{c}\text { Age } \\
\text { (years) }\end{array}$} & \multicolumn{2}{|c|}{$\begin{array}{l}\text { Height } \\
\text { (cm) }\end{array}$} & \multicolumn{2}{|c|}{$\begin{array}{c}\text { Weight } \\
(\mathrm{kg})\end{array}$} & \multicolumn{2}{|c|}{$\begin{array}{l}\text { Smokers } \\
\qquad N\end{array}$} & \multicolumn{2}{|c|}{$\begin{array}{l}\text { Drinkers } \\
\qquad N\end{array}$} & \multicolumn{2}{|c|}{$\begin{array}{c}\text { Daily } \\
\text { exposure } \\
\text { time }(\mathrm{h} / \mathrm{d})\end{array}$} & \multicolumn{2}{|c|}{$\begin{array}{c}\text { Total } \\
\text { operating } \\
\text { time (h) }\end{array}$} & \multicolumn{2}{|c|}{$\begin{array}{c}\mathrm{A}(8) \\
\left(\mathrm{m} / \mathrm{s}^{2}\right)\end{array}$} \\
\hline & Mean & SD & Mean & SD & Mean & SD & $N$ & $\%$ & $\mathrm{~N}$ & $\%$ & Mean & SD & Mean & SD & Mean & SD \\
\hline $\begin{array}{l}\text { Referents } \\
(N=455)\end{array}$ & 44.6 & 11.3 & 174 & 7.1 & 78.7 & 12.8 & 263 & 57.8 & 351 & 77.1 & . & $\cdot$ & . & . & . & . \\
\hline $\begin{array}{l}\text { Grinders } \\
(N=100)\end{array}$ & 46.9 & 8.8 & 175 & 6.5 & 80.7 & 11.1 & 44 & 44.0 & 75 & 75.0 & 1.7 & 1.1 & 6187 & 5308 & 1.6 & 0.6 \\
\hline $\begin{array}{l}\text { Shipyard workers } \\
(N=132)\end{array}$ & 48.8 & 8.9 & 174 & 6.9 & 82.7 & 13.4 & 68 & 51.5 & 86 & 65.2 & 1.7 & 1.2 & 6384 & 5432 & 1.9 & 0.9 \\
\hline $\begin{array}{l}\text { Caulkers } \\
(N=65)\end{array}$ & 52.5 & 5.6 & 172 & 7.9 & 78.7 & 11.8 & 28 & 43.1 & 51 & 78.5 & 3.4 & 1.2 & 12667 & 6787 & 4.2 & 0.9 \\
\hline $\begin{array}{l}\text { Mechanics } \\
(N=140)\end{array}$ & 49.5 & 8.9 & 174 & 6.7 & 79.9 & 12.0 & 63 & 45.0 & 102 & 72.9 & 1.9 & 1.2 & 8575 & 8373 & 1.7 & 0.7 \\
\hline $\begin{array}{l}\text { Construction workers } \\
(N=148)\end{array}$ & 50.3 & 8.6 & 173 & 5.7 & 82.8 & 12.6 & 58 & 39.2 & 107 & 72.3 & 1.7 & 1.1 & 5365 & 6602 & 2.8 & 1.3 \\
\hline $\begin{array}{l}\text { Quarry drillers } \\
(\mathrm{N}=41)\end{array}$ & 52.0 & 11.4 & 173 & 6.8 & 82.6 & 12.5 & 21 & 51.2 & 34 & 82.9 & 3.6 & 1.5 & 18623 & 14023 & 8.3 & 2.2 \\
\hline $\begin{array}{l}\text { Foundry workers } \\
(\mathrm{N}=31)\end{array}$ & 45.6 & 10.9 & 171 & 7.1 & 76.0 & 11.0 & 23 & 74.2 & 20 & 64.5 & 4.9 & 1.8 & 15388 & 12226 & 4.7 & 1.5 \\
\hline $\begin{array}{l}\text { Forest workers } \\
(N=165)\end{array}$ & 45.6 & 10.9 & 176 & 4.6 & 78.4 & 8.5 & 99 & 60.0 & 138 & 76.9 & 4.0 & 1.5 & 7665 & 5453 & 4.1 & 0.8 \\
\hline
\end{tabular}


finger (usually the 4th finger). The cold test was performed by pressurizing the air cuffs at a suprasystolic level $(210 \mathrm{~mm} \mathrm{Hg}, 27.9 \mathrm{kPa}$ ) and perfusing the water cuff initially at $30^{\circ} \mathrm{C}$ and then at 15 and $10^{\circ} \mathrm{C}$. After 5 minutes of ischemic cooling, the FSBP was measured on the test and reference fingers by a strain gauge plethysmographic technique. The change in systolic blood pressure in the test finger at 15 or $10^{\circ} \mathrm{C}\left(\mathrm{FSBP}_{\mathrm{t}, \mathrm{x}^{\circ}}\right)$ as a percentage of the pressure at $30^{\circ} \mathrm{C}\left(\mathrm{FSBP}_{\mathrm{t}, 30^{\circ}}\right)$, corrected for the change of pressure in the reference finger during the cold test $\left(\mathrm{FSBP}_{\mathrm{ref}, 30^{\circ}}-\right.$ $\mathrm{FSBP}_{\text {ref }, x^{\circ}}$ ), was calculated according the following formula:

$$
\begin{aligned}
& \text { FSBP\% }_{x^{\circ}}=\left[\left(\operatorname{FSBP}_{\mathrm{t}, \mathrm{o}^{\circ}} \cdot 100\right) / \mathrm{FSBP}_{\mathrm{t}, 30^{\circ}}\right. \\
& \left.-\left(\mathrm{FSBP}_{\text {ref }, 30^{\circ}}-\mathrm{FSBP}_{\mathrm{ref}, \mathrm{x}^{\circ}}\right)\right] .
\end{aligned}
$$

To avoid nicotine-induced vasoconstrictive effects on the digital arteries, tobacco users were recommended to refrain from smoking for at least 2 hours before being tested.

\section{Measurement and evaluation of vibration exposure}

Vibration measurements were performed on the most representative hand-held tools used by the workers in the workplace. Vibration was measured on metal-working tools (caulking tools, chipping hammers, impact wrenches, nut runners, scaling hammers, hand-held grinders and polishers), tools used in demolition, road construction and stone working (rock drills, road breakers, hammer drills, stone hammers, hand-held grinders and polishers), and tools used in forest work (chain saws, brush saws). Vibration measurements were taken on the tool handles in 3 orthogonal directions $(x, y$, and $z)$ during actual work operations according to the recommendations of the international standard ISO 5349 (12). From the one-third octave band frequency spectra $(6.3-1250 \mathrm{~Hz})$, the root mean square $(\mathrm{rms})$ of the frequency-weighted acceleration $\left(a_{\text {hw }}\right)$ was obtained after the weighting factors recommended by ISO 5349 were applied. The root-sum-of-squares of the frequency-weighted acceleration values for the 3 axes of vibration ( $a_{\mathrm{hww}}$ ) was then calculated. The values of $a_{h w v}$ ranged from 2.7 to $18.3 \mathrm{~m} / \mathrm{s}^{2} \mathrm{rms}$ in the manufacturing industry (foundry work, shipbuilding and repairing, mechanical engineering), from 4 to $19.4 \mathrm{~m} / \mathrm{s}^{2} \mathrm{rms}$ in the construction industry, from 10 to $17.9 \mathrm{~m} / \mathrm{s}^{2} \mathrm{rms}$ in quarrying, and from 4.2 to $9.8 \mathrm{~m} / \mathrm{s}^{2} \mathrm{rms}$ in forest work. The greater range of $a_{h w y}$ observed in the manufacturing and construction industries depends on the different types of tools (percussive, rotary, or mixed) used by the workers employed in such industrial activities. The duration of exposure to handtransmitted vibration was expressed in terms of hours per day and total operating time $(\mathrm{h} /$ day $\times$ day $/ y \times$ years $)$. Several information sources were used to estimate the duration of vibration exposure: workplace assessment questionnaires validated by interviews with employers and employees, examination of employment records, and direct observation of the work operations. The amount of fuel consumed by chain saws and brush saws during a typical workday was also used as an indirect indicator of daily exposure time for the forest workers.

Daily exposure to hand-transmitted vibration was assessed in terms of 8-hour energy-equivalent frequencyweighted acceleration [A(8) in $\mathrm{m} / \mathrm{s}^{2} \mathrm{rms}$ ] according to the British standard 6842 (13):

$$
\mathrm{A}(8)=\mathrm{a}_{\mathrm{l} w \mathrm{w}} \sqrt{\left(t / T_{(8)}\right)},
$$

where $t$ is the estimated daily exposure time in hours and $T_{(8)}$ is 8 hours.

\section{Statistical methods}

The data analysis was made with BMDP/Dynamic (release 7.0) and Stata (version 5.0) software. Continuous data were summarized as means and standard deviations. The difference between the group means was tested by a one-way analysis of variance or covariance and multiple comparison tests. The relation between variables expressed as means was assessed by weighted linear regression. The difference between categorical data tabulated in $2 \times k$ contingency tables was tested by the chi-square test. Cox's proportional hazard model was adapted to assess the association between vibration exposure and white fingers from cross-sectional data (14). Prevalence ratios and $95 \%$ confidence intervals, adjusted for several covariates, were estimated from the Cox regression coefficients and standard errors. A P-value of 0.05 was chosen as the limit of statistical significance.

\section{Results}

The preliminary data analysis showed that there were statistically significant differences between the surveyed populations with respect to vibration exposure (table 1). Total operating time with vibrating tools was greater for the caulkers, quarry drillers, and foundry workers than for the other job categories $(\mathrm{P}<0.001)$. The estimated mean value of $\mathrm{A}(8)$ was $8.3 \mathrm{~m} / \mathrm{s}^{2}$ for the quarry drillers who used only percussive tools, and it ranged between 2.8 and $4.7 \mathrm{~m} / \mathrm{s}^{2}$ for the occupational groups who handled forest machinery or a mixture of percussive and rotary tools (construction workers, caulkers, and foundry workers). The estimated $\mathrm{A}(8)$ averaged less than $2 \mathrm{~m} / \mathrm{s}^{2}$ for the grinders, mechanics, and shipyard workers who used only hand-held rotary tools. The difference in the mean values of $\mathrm{A}(8)$ between the vibration-exposed groups was highly significant $(\mathrm{P}<0.001)$.

Raynaud's phenomenon was found in $1.1 \%$ of the referents, while $17.2 \%$ of the vibration-exposed workers reported white fingers. The prevalence of white fingers varied from $9.0 \%$ for the grinders to $51.6 \%$ for the foundry workers (table 2). After adjustment for age, smoking, and drinking habits, the prevalence ratios for white fingers were significantly greater for all of the vibration-exposed groups 
when compared with the reference group $(\mathrm{P}<0.01)$. If the grinders are used as the reference category, the adjusted prevalence ratio for white fingers was greater for the quarry drillers, the foundry workers, the caulkers, and the forest workers. In these occupational groups, moreover, white fingers were more severe according to the stage system of the Stockholm scale.

When daily vibration exposure, expressed in terms of $A(8)$, was categorized according to the exposure levels proposed by the European Union (EU) directive for physical agents (15), the adjusted prevalence ratio for white fingers significantly increased with the increase of $A(8)$ (table 3 ). It is worth noting that white fingers were reported by only 2 vibration-exposed workers with an estimated $A(8)$ of $\leq 1 \mathrm{~m} / \mathrm{s}^{2}$ (ie, a vibration magnitude equal to or lower than the threshold value proposed by the EU directive). Among the workers included in this exposure category, the prevalence of white fingers was $2.4 \%$, a figure not significantly different from the prevalence of Raynaud's phenomenon in the referents.

A significant trend towards an increasing prevalence of white fingers with an increase in the duration of exposure was also observed for the vibration-exposed workers when total operating time with vibrating tools was categorized into a quartile distribution $(\mathrm{P}<0.001)$ (results not shown).

Table 4 presents the results of the cold test of the referents and the vibration-exposed groups. No significant difference in the mean values of FSBP at $30^{\circ} \mathrm{C}$ was found between the various groups. After adjustment for age, smoking, and drinking habits, the decrease in FSBP at 15 and $10^{\circ} \mathrm{C}$ was significantly greater in the vibration-exposed groups than in the reference group $(\mathrm{P}<0.001)$. In the whole sample of vibration-exposed workers, the subjects with white fingers exhibited a more powerful cold-induced digital vasoconstriction than those without white fingers, at both $15^{\circ} \mathrm{C}$ (mean FSBP $\%_{15^{\circ}}: 50.3$ versus $94.8 \%, \mathrm{P}<0.001$ ) and $10^{\circ} \mathrm{C}$ (mean FSBP $\%_{10}: 26.8$ versus $88.3 \%, \mathrm{P}<0.001$ ). No significant differences in either $\mathrm{FSBP} \%_{15^{\circ}}$ or $\mathrm{FSBP} \%_{10^{\circ}}$ were found between the workers with different stages of white fingers, even though the cold response in the digital arteries of the workers with white finger at stage 3 was stronger than that of the subjects with less severe white fingers (results not shown). None of the referents showed 0 digital pressure after the cold test, while the occurrence of the closing phenomenon in the digital arterial vessels of the vibration-exposed workers

Table 2. Prevalence of white fingers in the referents and the vibration-exposed groups. The prevalence ratios (PR) and $95 \%$ confidence intervals $(95 \% \mathrm{Cl})$ have been adjusted for age, smoking, and drinking habits.

\begin{tabular}{|c|c|c|c|c|c|c|c|c|c|c|c|c|}
\hline \multirow[t]{3}{*}{ Group } & \multicolumn{2}{|c|}{$\begin{array}{l}\text { Persons with } \\
\text { white fingers }\end{array}$} & \multicolumn{6}{|c|}{ Stages of white finger ${ }^{a}$} & \multirow[t]{3}{*}{$\mathrm{PR}_{1}^{\mathrm{o}}$} & \multirow[t]{3}{*}{$\begin{array}{l}95 \% \mathrm{Cl} \\
\text { for } \mathrm{PR}_{1}\end{array}$} & \multirow[t]{3}{*}{$P R_{2}{ }^{\mathrm{C}}$} & \multirow[t]{3}{*}{$\begin{array}{l}95 \% \mathrm{Cl} \\
\text { for } \mathrm{PR}_{2}\end{array}$} \\
\hline & \multirow[t]{2}{*}{$\mathrm{N}$} & \multirow[t]{2}{*}{$\%$} & \multicolumn{2}{|c|}{1} & \multicolumn{2}{|r|}{2} & \multicolumn{2}{|r|}{3} & & & & \\
\hline & & & N & $\%$ & $N$ & $\%$ & N & $\%$ & & & & \\
\hline Referents $(\mathrm{N}=455)$ & 5 & 1.1 & 3 & 0.7 & 2 & 0.4 & 0 & 0 & 1.0 & & . & . \\
\hline Grinders $(N=100)$ & 9 & 9.0 & 2 & 2.0 & 4 & 4.0 & 3 & 3.0 & 8.1 & $2.7-24.4$ & 1.0 & - \\
\hline Shipyard workers ( $N=132$ ) & 16 & 12.1 & 7 & 5.3 & 3 & 2.3 & 6 & 4.6 & 10.3 & $3.8-28.4$ & 1.3 & $0.6-2.9$ \\
\hline Caulkers $(N=65)$ & 15 & 23.1 & 1 & 1.5 & 9 & 13.9 & 5 & 7.7 & 18.6 & $6.7-51.9$ & 2.3 & $1.0-5.4$ \\
\hline Mechanics $(N=140)$ & 21 & 15.0 & 3 & 2.1 & 12 & 8.6 & 6 & 4.3 & 13.0 & $4.9-34.7$ & 1.6 & $0.7-3.4$ \\
\hline Construction workers $(N=148)$ & 11 & 7.4 & 2 & 1.4 & 4 & 2.7 & 5 & 3.4 & 6.1 & $2.1-17.8$ & 0.7 & $0.3-1.8$ \\
\hline Quarry drillers $(N=41)$ & 15 & 36.6 & 2 & 4.9 & 7 & $1 \overline{7} .1$ & 6 & 14.6 & 31.0 & $11.2-85.9$ & 3.8 & $1.6-8.7$ \\
\hline Foundry workers $(\mathbf{N}=31)$ & 16 & 51.6 & 1 & 3.2 & 1 & 3.2 & 14 & 45.2 & 39.8 & $14.3-111$ & 4.9 & $2.1-11.3$ \\
\hline Forest workers $(\mathrm{N}=165)^{\prime}$ & 38 & 23.0 & 8 & 4.9 & 18 & 10.9 & 12 & 7.3 & 20.0 & $7.8-51.2$ & 2.4 & $1.1-5.0$ \\
\hline
\end{tabular}

a Staged according to the Stockholm Workshop scale.

b Reference category: referents.

c Reference category: grinders

Table 3. Prevalence of white fingers among the users of vibrating tools according to daily vibration exposure expressed in terms of 8-hour energy-equivalent frequency-weighted acceleration $[A(8)] . A(8)$ has been divided into the exposure levels proposed by the European Union directive for physical agents (threshold level $=1.0 \mathrm{~m} / \mathrm{s}^{2}$, action level $=2.5 \mathrm{~m} / \mathrm{s}^{2}$, exposure limit value $=5.0 \mathrm{~m} / \mathrm{s}^{2}$ ). The prevalence ratios (PR) and 95\% confidence intervals (95\% Cl) have been adjusted for age, smoking, and drinking habits.

\begin{tabular}{|c|c|c|c|c|c|c|}
\hline & \multicolumn{2}{|c|}{$\begin{array}{l}\text { Persons with } \\
\text { white fingers }\end{array}$} & \multirow[t]{2}{*}{$\mathrm{PR}_{1}^{\mathrm{a}}$} & \multirow[t]{2}{*}{$\begin{array}{l}95 \% \mathrm{Cl} \\
\text { for } \mathrm{PR}_{1}\end{array}$} & \multirow[t]{2}{*}{$\mathrm{PR}_{2}{ }^{b}$} & \multirow[t]{2}{*}{$\begin{array}{l}95 \% \mathrm{Cl} \\
\text { for } \mathrm{PR}_{2}\end{array}$} \\
\hline & $N$ & $\%$ & & & & \\
\hline Referents $(\mathrm{N}=455$ ) & 5 & 1.1 & 1.0 & - & . & . \\
\hline \multicolumn{7}{|l|}{$A(8)\left(m / s^{2}\right)$} \\
\hline $\begin{array}{l}\leq 1.0(\mathrm{~N}=82) \\
1.0-2.5(\mathrm{~N}=316) \\
2.5-5.0(\mathrm{~N}=313) \\
>5.0(\mathrm{~N}=111)\end{array}$ & $\begin{array}{r}2 \\
35 \\
65 \\
43\end{array}$ & $\begin{array}{r}2.4 \\
11.1 \\
19.5 \\
38.7\end{array}$ & $\begin{array}{r}2.1 \\
9.5 \\
16.1 \\
32.3\end{array}$ & $\begin{array}{r}0.4-10.8 \\
3.7-24.3 \\
6.7-41.5 \\
12.8-81.9\end{array}$ & $\begin{array}{r}1.0 \\
4.5 \\
7.9 \\
15.5\end{array}$ & $\begin{array}{l}- \\
1.1-18.9 \\
1.9-32.5 \\
3.7-64.1\end{array}$ \\
\hline
\end{tabular}

a Reference category: referents.

b Reference category: $A(8) \leq 1.0 \mathrm{~m} / \mathrm{s}^{2}$. 
Table 4. Systolic blood pressure in the test finger at $30^{\circ} \mathrm{C}\left(\mathrm{FSBP}_{\mathrm{t}, 30^{\circ}}\right.$ in $\left.\mathrm{mm} \mathrm{Hg}\right)$ and at $15^{\circ} \mathrm{C}\left(\mathrm{FSBP} \%_{15^{\circ}}\right)$ and $10^{\circ} \mathrm{C}\left(\mathrm{FSBP} \%_{10^{\circ}}\right)$ as the percentage of the pressure at $30^{\circ} \mathrm{C}$ in the referents and the vibration-exposed groups. The number and percentage of workers showing the closing phenomenon in the digital arterial vessels at $10^{\circ} \mathrm{C}[0$ systolic blood pressure, $F S B P(0)]$ is also reported.

\begin{tabular}{|c|c|c|c|c|c|c|c|c|}
\hline \multirow[t]{2}{*}{ Group } & \multicolumn{2}{|c|}{$\mathrm{FSBP}_{\mathrm{t}, 30^{\circ}}(\mathrm{mm} \mathrm{Hg})$} & \multicolumn{2}{|c|}{ FSBP\% $\%_{15^{\circ}}(\%)$} & \multicolumn{2}{|c|}{ FSBP $\%_{10^{\circ}}(\%)$} & \multicolumn{2}{|c|}{$\operatorname{FSBP}(0)$} \\
\hline & Mean & SD & Mean & $\mathrm{SO}$ & Mean & SD & $\mathrm{N}$ & $\%$ \\
\hline Referents $(N=455)$ & 124 & 21.0 & 98.3 & 8.7 & 94.8 & 11.8 & 0 & 0 \\
\hline Grinders $(N=100)$ & 128 & 19.1 & 93.1 & 16.4 & 84.0 & 28.3 & 6 & 6.0 \\
\hline Shipyard workers $(N=132)$ & 121 & 20.5 & 87.3 & 26.2 & 82.0 & 29.2 & 11 & 8.3 \\
\hline Caulkers $(\mathrm{N}=65)$ & 129 & 19.1 & 84.1 & 29.9 & 74.5 & 34.6 & 8 & 12.3 \\
\hline Mechanics $(N=140)$ & 121 & 22.5 & 89.6 & 21.6 & 80.1 & 29.1 & 9 & 6.4 \\
\hline Construction workers $(N=148)$ & 127 & 22.0 & 92.6 & 20.9 & 86.4 & 25.1 & 7 & 4.7 \\
\hline Quarry drillers $(N=41)$ & 121 & 22.6 & 73.0 & 36.8 & 55.7 & 42.5 & 13 & 31.7 \\
\hline Foundry workers $(N=31)$ & 122 & 24.9 & 74.6 & 40.1 & 61.8 & 39.0 & 6 & 37.5 \\
\hline Forest workers $(\mathrm{N}=165)^{\prime}$ & 133 & 21.4 & 81.1 & $34.5^{*}$ & $70.6^{*}$ & 28.1 & $9^{* *}$ & 5.5 \\
\hline
\end{tabular}

a $1 \mathrm{mmHg} \approx 0.133 \mathrm{kPa}$.

${ }^{*} P<0.001$, one-way analysis of covariance (covariates: age, smoking and drinking habits); ${ }^{*} P<0.001$, chi-square test.

Table 5. Finger systolic blood pressure at $15^{\circ} \mathrm{C}\left(\mathrm{FSBP} \%_{15^{\circ}}\right)$ and $10^{\circ} \mathrm{C}\left(\mathrm{FSBP} \%_{10^{\circ}}\right)$ as the percentage of the pressure at $30^{\circ} \mathrm{C}$ in the users of vibrating tools according to daily vibration exposure expressed in terms of 8-hour energy-equivalent frequencyweighted acceleration $[A(8)] . A(8)$ is divided into the exposure levels proposed by the European Union directive for physical agents (threshold level $=1.0 \mathrm{~m} / \mathrm{s}^{2}$, action level $=2.5 \mathrm{~m} / \mathrm{s}^{2}$, exposure limit value $=5.0 \mathrm{~m} / \mathrm{s}^{2}$ ). The number and percentage of workers showing the closing phenomenon in the digital arterial vessels at $10^{\circ} \mathrm{C}[0$ systolic blood pressure, $\operatorname{FSBP}(0)]$ is also reported.

\begin{tabular}{|c|c|c|c|c|c|c|}
\hline \multirow[t]{2}{*}{$\begin{array}{l}\mathrm{A}(8) \\
\left(\mathrm{m} / \mathrm{s}^{2}\right)\end{array}$} & \multicolumn{2}{|c|}{$\begin{array}{c}\mathrm{FSBP} \%_{15^{\circ}} \\
(\%)\end{array}$} & \multicolumn{2}{|c|}{$\begin{array}{c}\text { FSBP\% } \%_{10} \\
(\%)\end{array}$} & \multicolumn{2}{|c|}{$\operatorname{FSBP}(0)$} \\
\hline & Mean & $\mathrm{SD}$ & Mean & $\mathrm{SD}$ & $N$ & $\%$ \\
\hline $\begin{array}{l}\leq 1.0(\mathrm{~N}=82) \\
1.0-2.5(\mathrm{~N}=316) \\
2.5-5.0(\mathrm{~N}=313) \\
>5.0(\mathrm{~N}=111)\end{array}$ & $\begin{array}{l}92.7 \\
91.2 \\
85.5 \\
72.7^{*}\end{array}$ & $\begin{array}{l}12.7 \\
22.1 \\
27.3 \\
39.0\end{array}$ & $\begin{array}{l}86.6 \\
84.5 \\
74.2 \\
61.9^{*}\end{array}$ & $\begin{array}{l}18.9 \\
27.5 \\
31.1 \\
38.2\end{array}$ & $\begin{array}{l}1 \\
17 \\
28 \\
23^{* *}\end{array}$ & $\begin{array}{r}1.2 \\
5.4 \\
8.9 \\
20.7\end{array}$ \\
\hline
\end{tabular}

* $P<0.001$, one-way analysis of covariance (covariates: age, smoking and drinking habits); ${ }^{* *} P<0.001$, chi-square test for trend.

ranged between $6.0 \%$ for the grinders and $37.5 \%$ for the foundry workers. Overall, 69 vibration-exposed workers $(8.4 \%)$ showed a complete closure of the digital arterial vessels during the cold test at $10^{\circ} \mathrm{C}$.

The univariate data analysis showed that the changes in FSBP at $15^{\circ}$ and $10^{\circ} \mathrm{C}$ were not related to either age or alcohol consumption for either the referents or the vibrationexposed workers. In both groups, $\mathrm{FSBP} \%$, mainly at $10^{\circ} \mathrm{C}$, was inversely associated with cigarette smoking $(\mathrm{P}<0.05)$.

A significant pattern of decreasing $\mathrm{FSBP} \%_{15^{\circ}}$ and FSBP $\%_{10^{\circ}}$ with increasing levels of A(8) was observed for the vibration-exposed workers (table 5). The occurrence of 0 systolic blood pressure during finger cooling to $10^{\circ} \mathrm{C}$ was found to increase with the increase of daily vibration exposure $(\mathrm{P}<0.001)$. In the various vibration-exposed groups, the mean change in FSBP at $10^{\circ} \mathrm{C}$ was found to be inversely related to the prevalence of white fingers (figure 1) and the estimated daily exposure to hand-transmitted vibration (figure 2). A similar inverse relation was found when FSBP $\%_{10^{\circ}}$ was regressed on the estimated mean total operating time with vibrating tools $\left(\mathrm{R}^{2}=0.70, \mathrm{P}=0.01\right)$.

\section{Discussion}

The findings of this study tend to confirm the conclusions of previous studies performed on smaller samples of vibrationexposed workers ( 3 -8), namely, the measurement of FSBP during local cooling can be considered an accurate laboratory test to differentiate between subjects with and without white fingers. This finding is also consistent with the results reported by other authors (16), who found that the digital pressure response to cooling was useful for the differential diagnosis of patients affected with nonoccupational vasospastic syndromes, such as cold sensitivity, primary Raynaud's phenomenon, and secondary Raynaud's phenomenon in scleroderma spectrum disorders. The cold test used in this study could not, however, differentiate between persons with different stages of white fingers, even if a trend (although not significant) for stronger cold-induced digital vasoconstriction with increasing severity of white fingers was observed for the affected workers.

Our findings indicate that, after adjustment for potential confounders, both vascular symptoms of white fingers and a cold-induced vasoconstrictor response of the digital arterial vessels were associated with vibration exposure. A major finding of this study was the evidence, among the exposed workers, of a significant increase in the abnormal response of the digital arterial vessels to cold with the increase of vibration exposure. This finding suggests a quantitative exposure-response relationship in which the exposure to hand-transmitted vibration is expressed as either $\mathrm{A}(8)$ or total operating time and the response is the group mean of the reduction of FSBP caused by cold provocation. In this epidemiologic survey the relations between $A(8)$ and vascular outcomes were mainly investigated because the energy-equivalent acceleration of vibration is the measure of exposure recommended by current standards and EU directives for hand-transmitted vibration $(12,13,15)$. In this context, it is worth noting that not only the pattern of the prevalence of white finger symptoms, but also the results of the cold test in the overall study population, seem to support the exposure limits for hand-transmitted vibration 


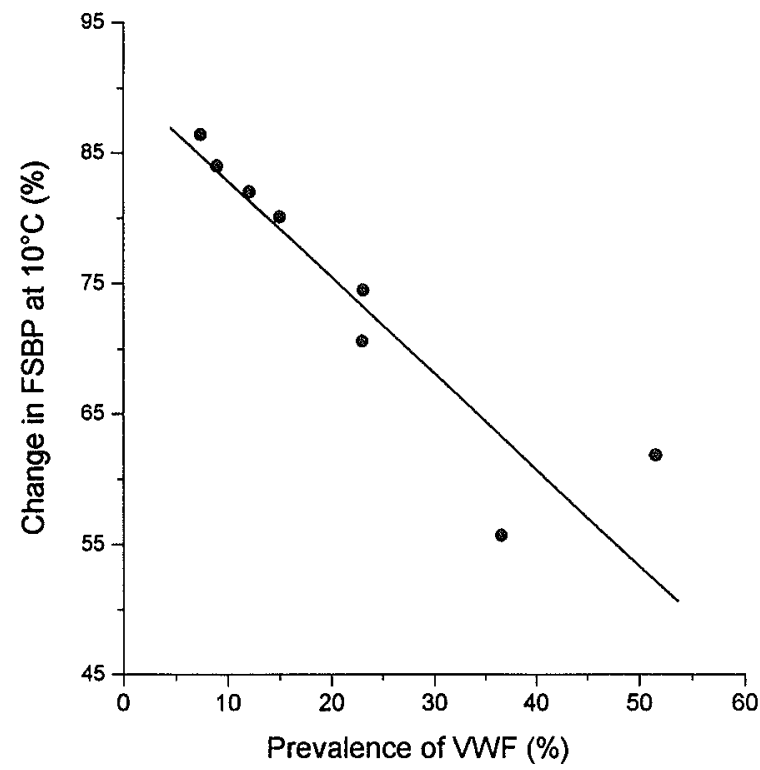

Figure 1. Relation between the cold response of digital arteries and the prevalence of vibration-induced white finger (VWF) in the vibration-exposed groups. The cold-induced digital arterial response is expressed as the mean change in finger systolic blood pressure (FSBP) at $10^{\circ} \mathrm{C}$ as a percentage of the pressure at $30^{\circ} \mathrm{C}$ [weighted linear regression: $\left.y=90.6-0.75 \times\left(R^{2}=0.87, P<0.001\right)\right]$

included in the proposal for an EU directive for physical agents (15).

In this study the risk for white fingers from hand-transmitted vibration was assessed on the basis of the magnitude, frequency, direction, and duration of vibration. It has been suggested that other physical variables, such as area of contact with vibration, contact force, environmental factors (eg, temperature) and use of gloves, can have a role in the etiopathogenesis of white fingers (17). A limitation of this study was the lack of control of these potential risk factors, even though there are currently no standardized methods to measure and evaluate their influence on the severity of hand-transmitted vibration (12). It can be hypothesized that the high

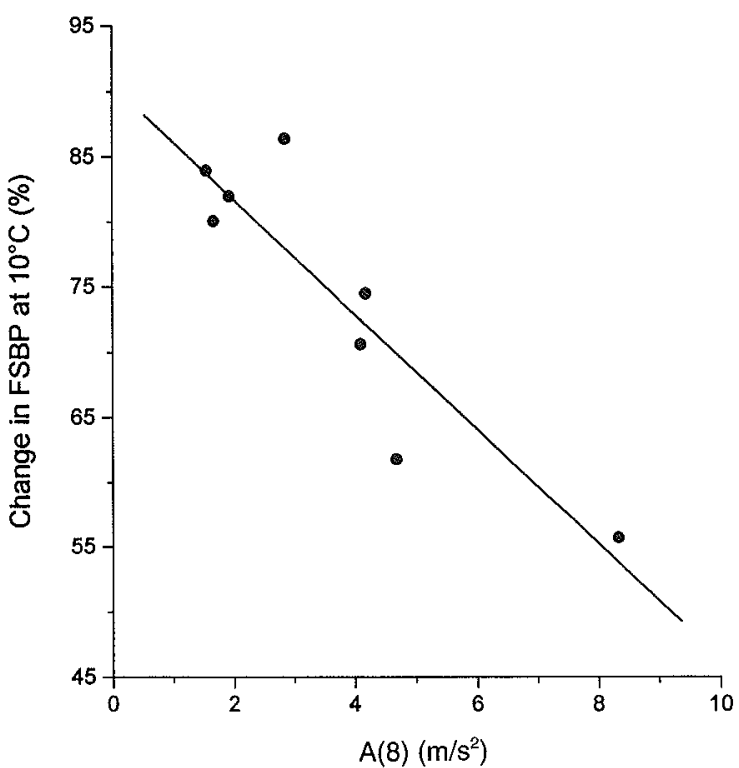

Figure 2. Relation between the cold response of digital arteries and estimated mean daily vibration exposure $(A(8))$ for the vibrationexposed groups. $A(8)$ is the 8-hour energy-equivalent frequencyweighted acceleration $\left(\mathrm{m} / \mathrm{s}^{2}\right)$. The cold-induced digital arterial response is expressed as the mean change in finger systolic blood pressure (FSBP) at $10^{\circ} \mathrm{C}$ as the percentage of the pressure at $30^{\circ} \mathrm{C}$. [weighted linear regression: $\left.y=91.1-4.4 \times\left(R^{2}=0.75, P<0.01\right)\right]$

grip and push forces exerted by the caulkers and the foundry workers on the handle of percussive tools, as well as the lower outdoor temperature to which the quarry drillers and the forest workers are usually exposed, can, at least partial$1 y$, contribute to the greater prevalence of white fingers and the stronger cold-induced digital vasoconstriction observed in these job categories.

On the basis of the results of the cold test of the healthy subjects in this study, the lower normal limits for FSBP\% ${ }_{15}$ were estimated to range between $81 \%$ (mean-2SD) and $72 \%$ (mean-3SD), whereas those for $\mathrm{FSBP} \%_{10^{\circ}}$ varied from $71 \%$ (mean-2SD) to 59\% (mean-3SD). Table 6 shows the sensitivity, specificity, and predictive values of the cold test to di-

Table 6. Sensitivity, specificity and predictive values of the finger systolic blood pressure (FSBP) measurements to detect cold-induced digital vasospasm in vibration-exposed workers. (FSBP $\%_{10^{\circ}}=$ the change in $\mathrm{FSBP}$ at $10^{\circ} \mathrm{C}$ as the percentage of the pressure at $30^{\circ} \mathrm{C}$ ). The discriminating thresholds for an abnormal cold response of the digital vessels were defined according to the lower normal limits of FSBP $\%_{10^{\circ}}$ estimated in a population of 455 healthy men [FSBP\% $\%_{10^{\circ}}: 70 \%$ (mean-2SD) or $60 \%$ (mean-3SD)]

\begin{tabular}{|c|c|c|c|c|c|c|c|c|c|}
\hline \multirow[t]{3}{*}{ Group } & \multirow{3}{*}{$\begin{array}{c}\text { Persons } \\
\text { with } \\
\text { white } \\
\text { fingers } \\
(\%)\end{array}$} & \multirow{2}{*}{\multicolumn{2}{|c|}{ 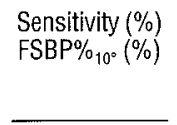 }} & \multirow{2}{*}{\multicolumn{2}{|c|}{ 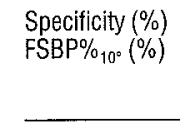 }} & \multicolumn{4}{|c|}{ Predictive value $(\%)$} \\
\hline & & & & & & \multicolumn{2}{|c|}{$\begin{array}{c}\text { Positive } \\
\text { FSBP } \%_{10^{\circ}}(\%)\end{array}$} & \multicolumn{2}{|c|}{$\begin{array}{c}\text { Negative } \\
\text { FSBP\% }{ }_{10^{\circ}}(\%)\end{array}$} \\
\hline & & $\overline{<70}$ & $<60$ & $<70$ & $<60$ & $<70$ & $<60$ & $<70$ & $<60$ \\
\hline Grinders $(N=100)$ & 9.0 & 100 & 88.9 & 90.1 & 92.3 & 50.0 & 53.3 & 100 & 98.8 \\
\hline Shipyard workers $(\mathrm{N}=132)$ & 12.1 & 100 & 81.3 & 93.1 & 95.7 & 66.7 & 72.2 & 100 & 97.4 \\
\hline Caulkers $(\mathrm{N}=65)$ & 23.1 & 100 & 100 & 96.0 & 98.0 & 88.2 & 93.8 & 100 & 100 \\
\hline Mechanics $(N=140)$ & 15.0 & 100 & 81.0 & 90.8 & 95.0 & 65.6 & 73.9 & 100 & 96.6 \\
\hline Construction workers $(N=148)$ & 7.4 & 100 & 90.9 & 93.4 & 95.6 & 55.0 & 62.5 & 100 & 99.2 \\
\hline Quarry drillers $(N=41)$ & 36.6 & 100 & 93.3 & 84.6 & 92.3 & 78.9 & 87.5 & 100 & 96.0 \\
\hline Foundry workers $(N=31)$ & 51.6 & 100 & 87.5 & 100 & 100 & 100 & 100 & 100 & 88.2 \\
\hline Forest workers $(\mathbb{N}=165)$ & 23.1 & 100 & 78.9 & 80.3 & 87.4 & 60.3 & 65.2 & 100 & 93.3 \\
\hline All groups $(\mathrm{N}=822)$ & 17.2 & 100 & 85.8 & 90.0 & 93.7 & 67.5 & 73.8 & 100 & 97.0 \\
\hline
\end{tabular}


agnose VWF in the various vibration-exposed groups with the estimated lower normal limits for $\mathrm{FSBP} \%{ }_{10^{\circ}}$ as diagnostic criteria to detect digital vasospasm during cold provocation. As expected, the predictive value of the cold test for diagnosing VWF was strongly dependent on the prevalence of the disease in the worker group; for similar values of sensitivity and specificity, the predictive value of a positive cold test tends to decrease with the reduction of the prevalence of VWF. In the whole sample of vibration-exposed workers $(\mathrm{N}=822)$, the sensitivity of the cold test in revealing VWF varied from $86 \%$ to $100 \%$, the specificity ranged from $90 \%$ to $94 \%$, and the positive predictive value fell between $68 \%$ and $74 \%$.

VWF is a peripheral vascular disorder which is included in a European list of occupational diseases (18). A definite diagnosis of VWF requires the support of both anamnestic and objective findings of digital vascular impairment and should be made by a qualified physician. The findings of this study may provide some suggestions to occupational health physicians who take on the responsibility of diagnosing VWF among vibration-exposed workers investigated in the context of either clinical work or epidemiologic studies. A reliable history of white fingers after the start of vibration exposure and an abnormal pressure response to finger cooling defined as $\mathrm{FSBP} \%_{10^{\circ}}<70 \%$, can be considered reasonable criteria for the diagnosis of VWF in epidemiologic investigations of vibration-exposed workers. A positive cold test should be an essential requirement for the diagnosis of VWF if screening methods are used to investigate VWF in epidemiologic studies, such as self-administered health questionnaires or interviews conducted by nonmedical professionals. The diagnosis of VWF can be only suspected without the support of a positive cold test. However, it should be pointed out that epidemiologic studies of subjective VWF retain great importance as they can provide data on the occurrence of suspected vascular disorders in vibration-exposed groups, and this information is very useful in the assessment of vibration hazards in the workplace and in the implementation of preventive measures. According to my clinical experience, it does not seem unreasonable to adopt more rigid diagnostic criteria when VWF has to be assessed among patients who undergo medical investigations for compensation purposes. Medicolegal considerations suggest that the result of the objective test of these patients should be clearly supportive of cold-induced digital vasospasm. Therefore, it can be proposed that, for insurance compensation purposes, the diagnosis of VWF should be based upon a true history of white fingers and a positive cold test with a 0 systolic blood pressure in the cooled finger or at least a reduction in FSBP at $10^{\circ} \mathrm{C}$ below $60 \%$ of the pressure at $30^{\circ} \mathrm{C}$.

\section{References}

1. Olsen N, Hagberg M, Ekenvall L, Futatsuka M, Harrison J, Nasu Y, et al. Clinical and laboratory diagnostics of vascular symptoms in- duced by hand-arm vibration [report from discussions in a working group]. In: Gemne G, Brammer AJ, Hagberg M, Lundström R, Nilsson T, editors. Proceedings of the Stockholm Workshop 94: handarm vibration syndrome: diagnostics and quantitative relationships to exposure. Solna: National Institute of Occupational Health, May 25-28, 1994. Stockholm: Arbetarskyddsverket, 1995;181—6. Arbete och Hälsa, 1995;5.

2. Maricq HR, Weinrich MC. Diagnosis of Raynaud's phenomenon assisted by color charts. J Rheumatol 1988;15:454—9.

3. Olsen N, Nielsen SL. Diagnosis of Raynaud's phenomenon in quarrymen's traumatic vasospastic disease. Scand J Work Environ Health 1979;5:249-56.

4. Olsen N, Nielsen SL, Voss P. Cold response of digital arteries in chain saw operators. Br J Ind Med 1982;39:82-8.

5. Ekenvall L, Lindblad LE. Vibration white finger and digital systolic pressure during cooling. Br J Ind Med 1986;43:280-3.

6. Kurosawa $Y$, Nasu $Y$, Nose T. Diagnostic value of finger systolic blood pressure in the assessment of vasospastic reactions in the finger skin of vibration-exposed subjects after finger and body cooling. Scand J Work Environ Health 1991;17:184-9.

7. Virokannas H, Rintamäki H. Finger blood pressure and rewarming rate for screening and diagnosis of Raynaud's phenomenon in workers exposed to vibration. BrJ Ind Med 1991;48:480-4.

8. Bovenzi M. Digital arterial responsiveness to cold in healthy men, vibration white finger and primary Raynaud's phenomenon. Scand J Work Environ Health 1993;19:271—6.

9. Pelmear PL, Taylor W, Wasserman DE, editors. Hand-arm vibration - a comprehensive guide for occupational health professionals. New York (NY): Van Nostrand Reinhold, 1992:201-14.

10. Gemne G, Pyykkö I, Taylor W, Pelmear PL. The Stockholm Workshop scale for the classification of cold-induced Raynaud's phenomenon in the hand-arm vibration syndrome (revision of the TaylorPelmear scale). Scand J Work Environ Health 1987;13:275-8.

11. Nielsen SL, Lassen NA. Measurement of digital blood pressure after local cooling. J Appl Physiol 1977;43:907-10.

12. International Organization for Standardization (ISO). Mechanical vibration - guidelines for the measurement and the assessment of human exposure to hand-transmitted vibration. Geneva: ISO, 1986. ISO 5349.

13. British Standards Institution (BSI). Measurement and evaluation of human exposure to vibration transmitted to the hand. London: BSI, 1987. BSI 6842.

14. Lee J, Chia KS. Estimation of prevalence rate ratios for cross-sectional data: an example in occupational epidemiology. Br J Ind Med 1993;50:861-2.

15. Council of the European Union. Amended proposal for a Council Directive on the minimum health and safety requirements regarding the exposure of workers to the risks arising from physical agents individual directive in relation to article 16 of the directive $89 / 391 /$ EEC. Brussels: European Community, 1994. Official Journal of the European Communities, 94/C 230/03, no C 230/3-29.

16. Maricq HR, Weinrich MC, Valter I, Palesch YY, Maricq JG. Digital vascular responses to cooling in subjects with cold sensitivity, primary Raynaud's phenomenon, or scleroderma spectrum disorders. J Rheumatol 1996;23:2068-78.

17. Griffin MJ. Measurement, evaluation, and assessment of occupational exposures to hand-transmitted vibration. Occup Environ Med $1997,54: 73-89$.

18. Commission des Communautés Européennes. Recommandation de la Commission du 22 mai 1990 concernant l'adoption d'une liste européenne des maladies professionnelles, (90/326/CEE). Brussels: Communautés Européennes, 1990. Joumal Officiel des Communautés Européennes, no L 160/39.

Received for publication: 28 July 1997 